*ak RMIS View/Frint Document Cover Sheet tow

This document was retrieved from the Documentation and Records Manaqement (DRM) ISEARCH System. It is intended for Information only and may not be the most recent or updated version. Contact a Document Service Center (see Hanford Info for locations) if you need additional retrieval information.

Accession \#: D196071640

Document \#: SD-GN-CM-20001

Title/Desc:

CONFIGURATION MGMT PROGRAM PLAN HANFORD SITE SYSTEMS ENGINEERING

Pages: 31 


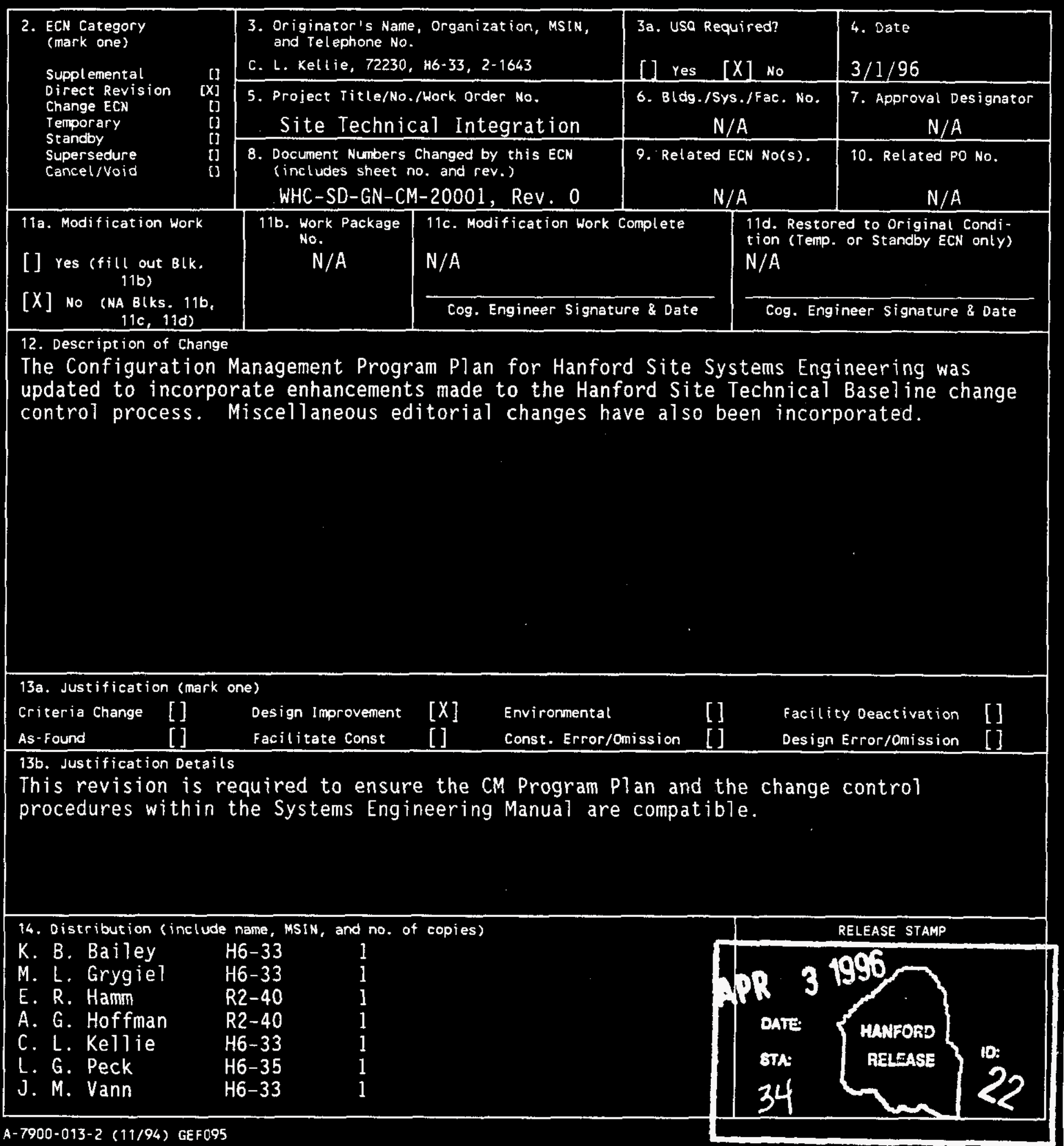




\section{ENGINEERING CHANGE NOTICE}

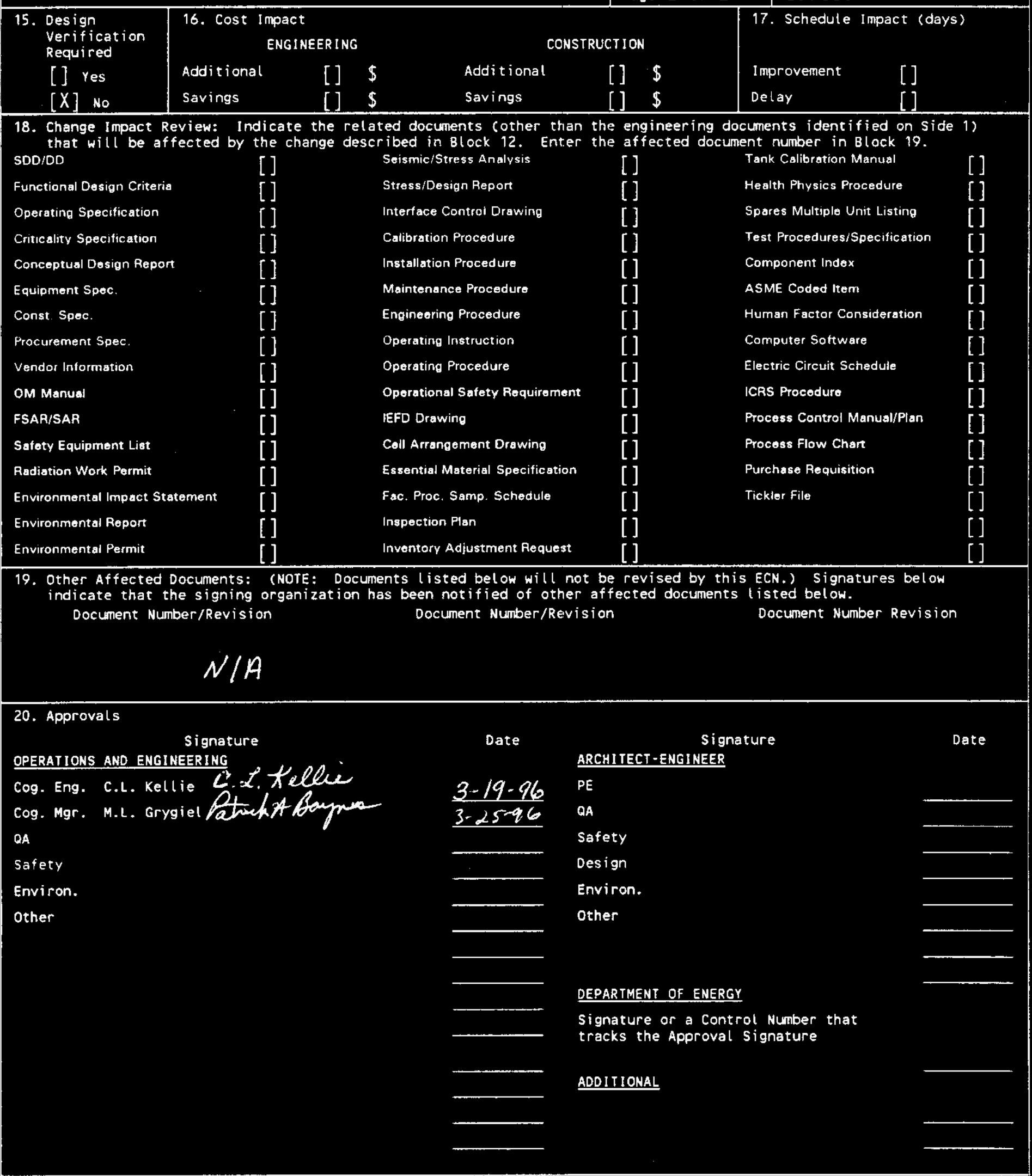




\title{
Configuration Management Program Plan for Hanford Site Systems Engineering
}

\author{
C.L. Kellie
}

Westinghouse Hanford Company, Richland, WA 99352

U.S. Department of Energy Contract DE-AC06-87RL10930
EDT/ECN: 197880
UC: $\quad U C-902$
Org Code: 72230
B\&R Code: EX7002000
Charge Code: DIM35
Total Pages: $2628 \omega_{4}, 3^{-96}$

Key Words: systems engineering, configuration management, RDD-100, Hanford Site Technical Engineering

Abstract: This plan establishes the integrated management program for the evolving technical baseline developed through the systems

engineering process. This configuration management program aligns with the criteria identified in the DOE Standard, DOE-STD-1073-93. Included are specific requirements for control of the systems engineering RDD_100 database, and electronic data incorporated in the database that establishes the Hanford Site Technical Baseline.

TRADEMARK DISCLAIMER. Reference herein to any specific commercial product, process, or service by trade name, trademark, manufacturer, or otherwise, does not necessarily constitute or imply its endorsement, recommendation, or favoring by the United States Governnent or any agency thereof or its contractors or subcontractors.

Printed in the United States of America. To obtain copies of this document, contact: WHC/BCS Document Control Services, P.O. Box 1970, Mailstop H6-08, Richland WA 99352, Phone (509) 372-2420; Fax (509) 376-4989.
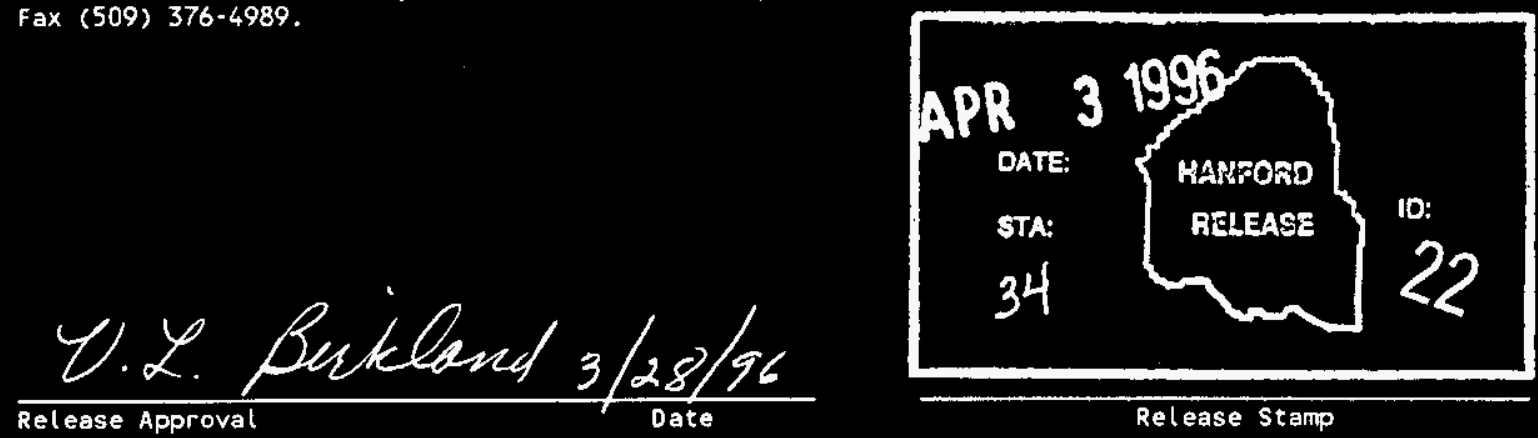

Approved for Public Release 
(2) Title

Configuration Management Program Plan for Hanford Site Systems Engineering

CHANGE CONTROL RECORD

\begin{tabular}{|c|c|c|c|c|c|}
\hline & \multirow{2}{*}{ Revision } & & \multirow{2}{*}{ Description of Change - Replace, Add, and Delete Pages } & \multicolumn{2}{|c|}{ Authorized for Release } \\
\hline & & & & (5) Cog. Engr. & (6) Cog. Mgr. \\
\hline & 1 & (7) & $\begin{array}{l}\text { Complete revision of the Configuration } \\
\text { Management Program Plan for Hanford } \\
\text { Site Systems Engineering to } \\
\text { incorporate enhancements made to the } \\
\text { Hanford Site Technical Basel ine change } \\
\text { control process. Miscellaneous } \\
\text { editorial changes have al so been } \\
\text { incorporated. } \quad E C N-197880\end{array}$ & $\begin{array}{l}\text { C.t Kellie } 3 / 9 / 96 \\
\text { c.L. Kellie }\end{array}$ & $\begin{array}{l}\text { PA Gaypea 3/25/96 } \\
\text { M.L. Grygie] }\end{array}$ \\
\hline & $O$ & & $E \Delta T-608582, \quad 11-29.94$ & & \\
\hline & & & & & \\
\hline & & & & & \\
\hline & & & & & \\
\hline & & & & & \\
\hline & & & & & \\
\hline & & & & & \\
\hline & & & & & \\
\hline & & & & & \\
\hline & & & & & \\
\hline & & & & & \\
\hline & & & & & \\
\hline & & & & & \\
\hline & & & & & \\
\hline & & & & & \\
\hline & & & & & \\
\hline & & & & & \\
\hline & & & & & \\
\hline & & & & & \\
\hline & & & & & \\
\hline & & & & & \\
\hline & & & & & \\
\hline & & & & & \\
\hline & & & & & \\
\hline & & & & & \\
\hline & & & & & \\
\hline & & & & & \\
\hline & & & & & \\
\hline & & & & & \\
\hline
\end{tabular}


WHC-SD-GN-CM-2000I

Rev. I

CONFIGURATION MANAGEMENT PROGRAM PLAN

FOR

HANFORD SITE SYSTEMS ENGINEERING

March 1, 1996

WESTINGHOUSE HANFORD COMPANY 
CONTENTS

\subsection{INTRODUCTION}

1.1 PURPOSE

1.2 SCOPE

2.0 ROLES AND RESPONSIBILITIES

2.1 U.S. DEPARTMENT OF ENERGY, RICHLAND OPERATIONS OFFICE

2.2 WESTINGHOUSE HANFORD COMPANY

2.3 OPERATIONS AND MAINTENANCE PROGRAMS

2.4 SITE TECHNICAL INTEGRATION

2.5 DIVISION AND DEPARTMENT MANAGEMENT

2.6 FACILITY/PLANT ORGANIZATIONS

2.7 DESIGN ENGINEERING

2.8 QUALITY ASSURANCE

2.9 BUS INESS MANAGEMENT

2.10 BCS RICHLAND (BCSR)

3.0 CONFIGURATION MANAGEMENT PROGRAM DESCRIPTION 10

3.1 PROGRAM MANAGEMENT

3.1.1 Program Planning

3.1.2 Interfaces

3.1.3 Databases

3.1.4 Technical Baseline

3.1.5 Procedures and Training

DESIGN REQUIREMENTS

3.2.1 Design Basis

3.2.2 Requirements

3.2.3 Systems and Process Boundaries 12

3.3 DOCUMENT CONTROL

3.3.1 Identification of Documents and Computer Software .. 13

3.3.2 Storage

3.3.3 Control and Tracking

3.3.4 Document Retrieval

3.4 CHANGE CONTROL

3.4.1 Identification of Changes

3.4.2 Change Processing Procedures

3.4.3 Technical Change Reviews

3.4.4 Management Change Reviews

3.4.5 Implementation

3.4.6 Change Control Tracking

3.5 ASSESSMENTS

4.0 SOFTWARE CONF IGURATION MANAGEMENT 18

4.1 DESCRIPTION OF THE HANFORD SITE TECHNICAL BASELINE DATABASE 18

4.2 CONTROL OF HANFORD AND VENDOR APPLICATION SOFTWARE

4.3 CONTROL OF DATA

4.3.1 Functional Control of Data

18

4.3.2 Administrative Control of Data

18

19

4.4 HANFORD SITE TECHNICAL BASELINE DATABASE VERSION CONTROL

4.5 PROCEDURE REQUIREMENTS

$\begin{array}{lll}5.0 & \text { REFERENCES } & 23\end{array}$

$\begin{array}{lll}6.0 & \text { BIBLIOGRAPHY } & 24\end{array}$

Glossary $\quad 25$ 


\subsection{INTRODUCTION}

This plan describes the integrated Configuration Management (CM) Program that supports the application of systems engineering (SE) to ensure that the cleanup component of the Hanford Site mission is achieved. The CM program provides the SE process phased and graded control that ensures the integrity of a progressive technical baseline definition through the evolution of a systematic life cycle engineering process (see Hanford Site Systems Engineering Management Plan). The Hanford Site Configuration Management Program Plan (CMPP) aligns with the criteria defined in the DOE Standard, DOE-STD-1073-93, and is responsive to the requirements of DOE Directives DOE 4700.1, DOE 5700.6C, RLPD 4900.1, RLID 5000.12, and RLID 4700.1A.

\subsection{PURPOSE}

The CM Program described in this plan documents, controls, and statuses the Hanford Site mission-based technical baseline produced from the Hanford Site SE process. The CMPP integrates technical and administrative controls to establish and maintain technical consistency among requirements, physical configuration, and documentation (including computer software). This plan prescribes the program to document, communicate, and control the established technical baseline. The CM Program is designed to ensure that uniform criteria is applied to the identification and documentation of the technical baseline; control and status technical baselines and changes to these baselines to ensure that design, performance, and operational requirements are satisfied; assess that the technical baseline is verified in accordance with prescribed requirements; and define roles and responsibilities necessary for the successful execution of this program.

\subsection{SCOPE}

The CMPP is applicable to the Hanford Site SE process at the Hanford Site level, the Hanford Site Technical Baseline (HSTB), and the Hanford Site Technical Baseline Database (HSTBD). Each Program is responsible for using CM processes for SE activities that are compatible with this CMPP. The CMPP applies throughout the life of Hanford's mission. The life cycle begins with the initial development of the mission statement and continues through the evolution of the HSTB through environmental restoration. This plan provides the minimum requirements for establishing methods and procedures to:

1. Establish the program architecture for $\mathrm{CM}$.

2. Identify, control, and status the technical baseline.

3. Provide a systematic discipline for control of changes to the technical baseline.

4. Identify and control physical, functional, and organizational interfaces within the CM program.

5. Ensure the adequacy of $\mathrm{CM}$ functional elements and the conformance of Hanford Site documentation and computer software to their respective requirements. 
The CM Program is comprised of five basic elements: "program management," "design requirements," "document control, "change control," and "assessments" and the two adjunct programs of "design reconstitution" and "material condition and aging" management. The adjunct programs are recovery programs not associated with the early formulation and definition of programs. Therefore, these adjunct programs will not be addressed in this initial program plan. This plan will be modified in subsequent revisions to adequately control the technical baseline prescribed through the SE process and will address the two adjunct programs when appropriate. 


\subsection{ROLES AND RESPONSIBILITIES}

Organizational roles and responsibilities are established in this $p l a n$ to generally describe the functional organizations' duties, responsibilities, and interactions required to support the implementation of the CM program.

\subsection{U.S. DEPARTMENT OF ENERGY, RICHLAND OPERATIONS OFFICE}

RL has the authority and responsibility to formulate and evaluate the execution of the CM Program. RL wi1l:

1. Ensure execution of a CM Program to achieve Hanford's mission objectives.

2. Provide CM requirements applicable to activities performed by the Hanford Site SE process.

\subsection{WESTINGHOUSE HANFORD COMPANY}

WHC, the Maintenance and Operating (M80) contractor, will manage the CM Program by ensuring development and establishment of requirements and appropriate implementing procedures that address CM process methodologies and responsibilities for WHC-managed facilities, programs, and projects.

\subsection{OPERATIONS AND MAINTENANCE PROGRAMS}

The Operations and Maintenance Programs will develop the WHC CM program that provides a consistent and graded approach for all WHC-managed facilities, programs, and projects to achieve the Hanford mission. The CM function of Operations and Maintenance Programs will:

1. Establish and implement an integrated CM Program in accordance with the requirements of applicable DOE Directives and the criteria defined in the DOE Standard, DOE-STD-1073-93.

2. Identify and manage boundaries and interfaces within the uniform Hanford Site CM approach with other Hanford programs or projects (see WHC-EP-0722, "Systems Engineering Functions and Requirements for the Hanford Cleanup Mission: First Issue").

3. Develop and maintain CM functions, processes, interfaces, and procedures for the site CM process.

4. Ensure that complete, approved technical baseline documents and computer software exist within the CM program.

5. Ensure controls for the Hanford Site SE process support the evolving HSTB.

\subsection{SITE TECHNICAL INTEGRATION}

Site Technical Integration has responsibility for the Site SE process as defined in the Hanford Site Systems Engineering Management Plan. Site Technical Integration will: 
1. Develop and maintain CM functions, processes, interfaces, and procedures.

2. Ensure configuration controls for the Hanford Site SE process which supports the evolving HSTB.

3. Manage the HSTBD to:

- Establish and maintain controls for maintenance and version control of the software.

- Evaluate the changes to the software.

- Ensure implementation and testing of approved changes.

- Verify installation of revisions to the database.

- Assign a System Administrator to the HSTBD.

- Provide access control for the HSTBD.

4. Ensure completeness, accuracy, and validity of the HSTB documents and computer software submitted to the CM organization.

5. Approve changes to the HSTB.

\subsection{DIVISION AND DEPARTMENT MANAGEMENT}

Divisions and departments will implement the criteria and requirements of the CM Program identified in this program plan. All WHC divisions and departments will implement the CM Program to ensure that technical baseline documents, computer software, and hardware are maintained and controlled throughout their 1 ife cycle.

\subsection{FACILITY/PLANT ORGANIZATIONS}

The facility/plant organizations are the Design Authorities and will ensure that a complete, accurate, and valid technical baseline is supported, maintained current, and controlled by the CM Program. Facility/plant organizations will also perform tasks in accordance with the requirements identified for the use of and interface with the HSTBD. User facilities and plants provide database administrators, identify user groups, and provide training required for an optimal level of performance.

\subsection{DESIGN ENGINEERING}

Design Engineering is a generic term used to describe the engineering organization responsible for a conceptual, definitive, or sustained design. Design Engineering will:

1. Ensure that appropriate reviews and approvals are obtained for original designs and subsequent changes.

2. Assist in the development and maintenance of the approved technical baseline during design development phases. 
3. Identify and manage technical boundaries and interface characteristics.

\subsection{QUALITY ASSURANCE}

Quality Assurance is responsible for site quality issues and will:

1. Develop audit plans, checklists, and assessment criteria and conduct periodic assessments of $\mathrm{CM}$ requirements and implementing procedures and processes when requested by $\mathrm{CM}$.

2. Verify that procedures related to $\mathrm{CM}$ are implemented in accordance with WHC requirements and procedures.

3. Participate in the CM functional processes of change control and design verification through reviews, inspections, audits, and surveillances.

\subsection{BUSINESS MANAGEMENT}

Business management will develop and maintain cost and schedule baselines through the Basel ine Development and Management Systems organizations. Business management will control and process programmatic cost and schedule changes that affect these established baselines.

\subsection{BCS RICHLAND (BCSR)}

BCSR will:

1. Establish and manage technical baseline document processing, distribution, record storage, retrieval, and microfilming.

2. Provide vault storage for documentation and computer software media. 


\subsection{CONFIGURATION MANAGEMENT PROGRAM DESCRIPTION}

The CM Program establishes consistency among requirements, physical configurations, and documentation (including computer software), and maintains this consistency to support the Hanford Site mission. The CM Program is composed of five basic elements as identified in the following paragraphs.

\subsection{PROGRAM MANAGEMENT}

For the purposes of this plan, the program management element for the Hanford Site SE process directs and monitors the development and implementation of the overall CM Program. In addition, the program establishes the scope of information to be included in the CM process; defines CM concepts and terminology; identifies and controls CM organizational and programmatic interfaces; establishes the policy and criteria for required databases; and develops and maintains CM procedures.

\subsubsection{Program Planning}

Since the products of the formulation and definition phase of the technical baseline is primarily information (technical baseline documents, software, etc.) that define system concepts and requirements, planning of the progressive CM Program is commensurate with the baseline scope at any phase of evolution.

\subsubsection{Interfaces}

Configuration management interfaces with the Hanford Site SE initiatives by providing procedures to identify, release, change, status, store, and assess information that is produced using the SE process.

\subsubsection{Databases}

Databases (e.g., technical baseline documents, requirements, and change request [CR] status) are required to identify, store, control, status, and retrieve selected information important to CM.

1. The engineering release system database (ERSDB) will be used to status all approved and released technical baseline documents and engineering change notices (ECN).

2. The HSTBD is used to perform SE and develop and maintain the HSTB. See paragraph 4.0 of this plan for a brief description of the HSTBD and how it is controlled.

\subsubsection{Technical Baseline}

The HSTB is the reference set of information that evolves with the Hanford Site's facilities, programs, and projects. The HSTB provides a controlled frame of reference to progressively expand the system definition and design. Specific details regarding the HSTB evolution process are identified in the Hanford Site Systems Engineering Management Plan (draft). 
Technical baseline documents and software in the baseline will be prepared in accordance with the applicable procedures. As development of the baseline evolves, required documentation and software will be developed or changed and controlled throughout the facilities', programs' or projects' life cycle identified by the related CM program.

\subsubsection{Procedures and Training}

Procedures are necessary to address the CM functions of program management, design requirements, document control, change control, and assessments. A phased and graded implementation is necessary for the successful execution of the CM Program. Specific criteria required for procedures to support the computer software implementation needs are addressed in paragraph 4.0 of this plan.

As procedures and related $\mathrm{CM}$ processes are established, associated training will be required to communicate objectives and expectations and to ensure effective implementation. The CM function will develop program training that will be provided in several levels of detail on the CM concepts, roles and responsibilities, terminology, and implementing procedures.

Database training will be developed by SE for all operators and users of the HSTBD. The training will address the maintenance of the computer software and all related procedures. Training will also be developed and provided to administrators and users to maintain integrity of the database and the electronic data. Individuals assigned the responsibilities identified in this paragraph will have the necessary training to qualify for performing the identified tasks.

\subsection{DESIGN REQUIREMENTS}

The design requirements element identifies and controls design basis information and the products generated from the SE process. The SE process is the technical and management process that transforms the Hanford Site mission statement into an integrated technical baseline.

\subsubsection{Design Basis}

The Design Basis consists of:

1. Inputs - Those specific criteria, limits, bases, or other initial requirements (such as specific functional requirements, specific codes and standards, and specific regulatory commitments) upon which the design output documents are based.

2. Constraints - Those general restrictions and limits to the process that ensure the consistency and quality of the definition (such as the regulatory commitments, quality assurance requirements, engineering procedures, and good practices). 
3. Design Analysis and Calculations - Those intermediate design products that are necessary to convert the design inputs and constraints into appropriate and complete design outputs. Design analysis and calculations consist of a wide variety of engineering analyses, calculations, studies, reports, and technical review checklists necessary to perform complete engineering design.

The design basis will be formally documented, released, and correlated with the design output documents, and maintained.

1. A management review will be performed to determine the adequacy of the design basis.

2. The design basis for new or modified requirements will be established and documented (via text documents or database) as they are developed.

\subsubsection{Requirements}

Requirements reflected in the design outputs (drawing, specifications, supporting documents, and software) are the products of the SE process. These requirement outputs are the composite result of various organizations consideration of the inputs, constraints, and analys is and calculations. Requirements will be formally documented, released, and maintained.

1. A management review will be performed to determine the adequacy of the requirements.

2. The requirements will be correlated with the associated design basis in the HSTBD.

\subsubsection{Systems and Process Boundaries}

The interface boundaries of the information in the technical baseline are required to be controlled. As the technical baseline is developed and requirements are defined, their relationship to each other shall be evaluated to determine if interface controls are required. Hanford site interface control to support SE shall be established in accordance with WHC-CM-6-1, EP-1.5, for technical baseline documents and software.

\subsection{DOCUMENT CONTROL}

The document control element identifies and maintains the information of the HSTB developed by the SE process. The document control function establishes criteria to identify, store, track, and retrieve technical baseline information so that it is available for use in making decisions, evaluating proposed changes, and recreating the technical baseline.

\subsubsection{Identification of Technical Baseline Documents and Computer Software}

All information within the CM Program will have unique identification numbers to perform document retrieval, statusing, change development, and linkages to other documents or software data. Technical baseline documents and software included in the Hanford Site CM Program will be identified and controlled. 
1. A graded approach will identify the technical baseline document types and the specific documents that are required for each evolution phase of the technical baseline.

2. Each type of technical baseline document and software will identify owners.

3. The technical content of assigned technical baseline documents and software will be verified by owners.

4. Each technical baseline document will be identified in accordance with WHC-CM-6-1, EP-1.1.

5. All computer software and associated electronic data will be controlled in accordance with WHC-CM-3-10.

\subsubsection{Storage}

1. Responsibility for technical baseline document archival storage, permanent storage for one-of-a-kind records, access control, and microfilming of record documents will be assigned to BCSR and documented in WHC-CM-3-5.

2. Original/master copies of technical baseline documents, including computer software, will be stored and protected in accordance with WHC-CM-3-5, Section 5.0.

\subsubsection{Control and Tracking}

1. Hanford Site SE uses the WHC Configuration Documentation Work Station (COWS) for release, retention, and retrievability of technical baseline documents. The requirements for use of this system are specified in WHC-CM-6-1, EP-1.7, for technical baseline documents, and paragraph 4.0 of this plan for computer software.

2. The WHC ERSDB will be used to release, control, and status all technical baseline documents and approved changes to those documents . 


\subsubsection{Document Retrieval}

1. Hanford Site Technical Basel ine documents and software files will be retrieved in accordance with WHC-CM-3-5, Section 5.0.

2. The required retrieval times for each technical basel ine document will be established based upon the priorities established by the technical baseline document owners and users.

\subsection{CHANGE CONTROL}

The change control element maintains consistency among the requirements, the physical configuration, and documentation (including computer software). For adequate control, each change is identified, technically reviewed, approved (or disapproved or deferred), and documented so that the configuration is maintained. Change control of the technical baseline is the systematic evaluation and coordination process of maintaining the previously established technical, cost, and schedule baselines and identifying and controlling all changes to these baselines.

The Hanford Site-level portion of the HSTB specifies the Hanford Site functions down to the point where functions can be assigned to various Programs (e.g., from 0 to 4.\#). These top-level Program functions are controlled at the Hanford Site level (see Figure 1). Interfaces external to each program are also controlled at the Hanford Site level. If a requested change will impact a top level program function or interface specified in the HSTB, the change proposal is submitted to the Hanford Site-level change control process.

Figure 1. Change Control Hierarchy.

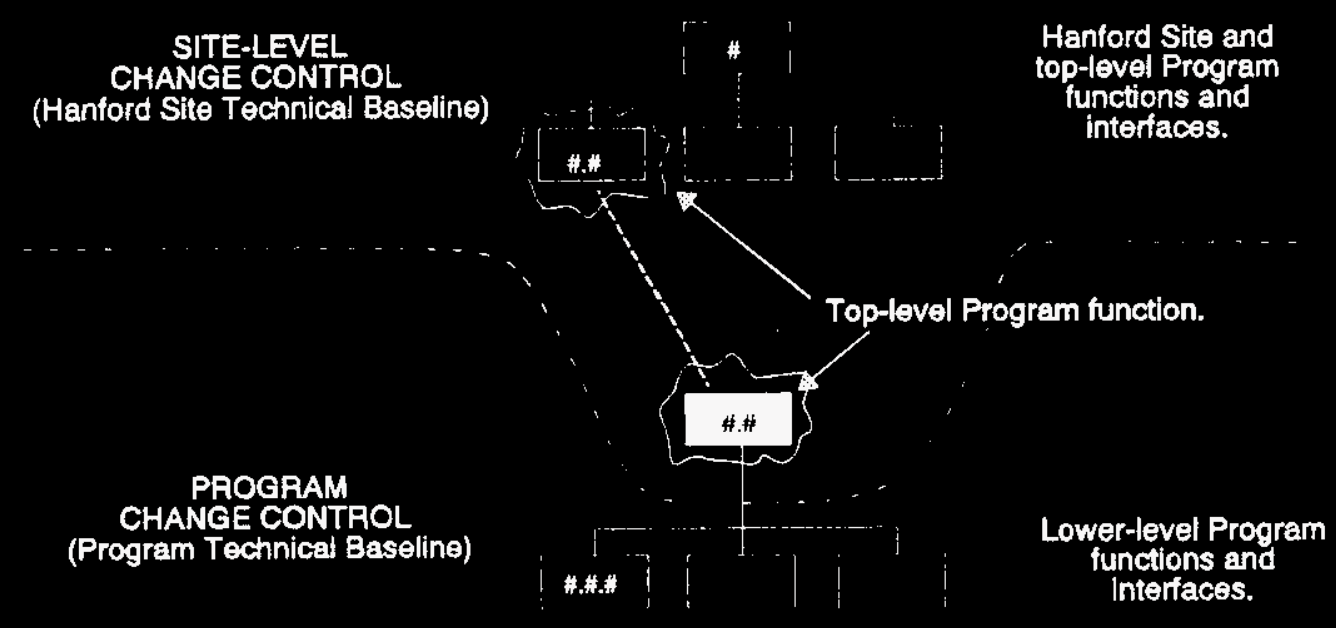




\subsubsection{Identification of Changes}

The initiator of a proposed change to the technical baseline will provide sufficient information with the change package to permit the approval authorities to adequately review the change proposal. The information will include, but is not limited to:

1. The ECN or CR that describes the change and provides justification for it.

2. The correspondence that requires or requests the change to be made a part of the change package. Examples of correspondence are DOE Directives, Tri-Party Agreements, or changes to those agreements, audits, laws and regulations, safety analyses, etc.

3. Results of analyses and/or calculations.

4. Due dates, constraints, alternatives, and the impact if the change is or is not implemented by the due date.

\subsubsection{Change Processing Procedures}

1. Technical Changes. Technical changes affecting technical baseline documents that have no impact on programmatic baselines will be processed in accordance with WHC-CM-6-1. Technical changes affecting computer software will be processed in accordance with paragraph 4.0 of this plan. Technical changes that, upon further review, result in a programmatic impact, will be processed as a programmatic change as described below.

2. Programmatic Changes. Programmatic changes against cost and schedule baselines will be processed in accordance with WHC-CM-2-5.

\subsubsection{Technical Change Reviews}

All changes will be evaluated to:

1. Determine the technical validity of the change.

2. Identify all affected baseline information, associated documentation, and software.

3. Determine the appropriate post-implementation acceptance criteria.

4. Identify the impact to other programs not associated with the original change proposal.

5. Determine the impact on the technical, cost, and schedule baselines and other baseline information in the CM program.

6. Ensure that mission objectives will be met or that the change will not interfere with the accomplishment of the mission. 


\subsubsection{Management Change Reviews}

Management will review the proposed technical change (including impacts to cost and schedule baselines) to verify that the technical reviews have been performed adequately, that the proposed change is complete and ready for implementation, and that any external approvals are obtained before implementation.

\subsubsection{Implementation}

Approved technical changes will be implemented in accordance with WHC-CM-6-1 and WHC-CM-3-10. Approved programmatic changes will be implemented in accordance with WHC-CM-2-5.

\subsubsection{Change Control Tracking}

The current status of all technical changes will be tracked by SE Management.

1. The baseline status of approved ECNs against any technical baseline document released through the ERSDB will be available through the CDWS.

2. All released ECNs will be tracked by the CDWS until they are incorporated. To maintain two-way traceability, any ECN that has been authorized by a CR will reference the authorizing CR number.

3. Each CR will reference the correspondence that was used as the basis for the CR. These references will be included in the ERSDB and $C R$ logs.

4. A CR status database will be maintained by SE Management to track the status of proposed changes including those changes that are later found to impact programmatic baselines.

5. A status report will be prepared by SE Management and distributed as requested. The report will contain the technical baseline document number; revision; title; owner; CR number, summary description, and status; and ECN number, status, release date, incorporation date, summary description, and related ECN numbers.

\subsection{ASSESSMENTS}

The assessments element measures the CM Program effectiveness in establishing and maintaining the $C M$ relationships. The assessment element assists in defining the needs of the CM program. Assessments are also used to validate the accuracy of the technical baseline information.

1. Initial Assessments. During the planning for the development of the CM Program, initial assessments will be conducted to determine the strengths and weaknesses of the existing

Hanford Site CM functions and processes.

2. Post-implementation Assessments. Post-implementation assessments will be performed for each CM program element to determine if the 
programs and procedures are effective in accomplishing the $\mathrm{CM}$ functions.

3. On-going Assessments. Following CM implementation, assessments shall be performed periodically to measure the overall CM Program effectiveness and to determine if the degree of control is adequate and appropriate.

Hanford Site SE documentation will be subject to verification in accordance with approved procedures and WHC-CM-6-1, EP-4.1. Deficiencies and/or discrepancies disclosed by the review will be resolved and documented. 
WHC-SD-GN-CM-20001

Rev. 1

\subsection{SOFTWARE CONFIGURATION MANAGEMENT}

\subsection{DESCRIPTION OF THE HANFORD SITE TECHNICAL BASELINE DATABASE}

The Hanford Site Technical Baseline Database (HSTBD) consists of the vendor-supplied application software, Hanford application software, standardized operating system and hardware options, a schema definition that provides parameters and rules that support shared use, and resident data.

The systems engineering software includes a number of components. These components operate together to support the management of information to enable: (1) requirements and functional decomposition, (2) scenario descriptions, (3) full conceptual system model, (4) full integrated systems model, and (5) application to support the design, test, implementation and specifications including: (1) functions and requirements, (2) scenario performance, (3) dynamically verified system, and (4) dynamically verified manufacturing and logistics. In addition, the system supports the management of risk decisions and issue resolution.

Since the HSTB is maintained on the HSTBD, it is necessary to control the application software as well as the HSTB data.

\subsection{CONTROL OF HANFORD AND VENDOR APPLICATION SOFTWARE}

Safeguards have been incorporated in the HSTBD structure to ensure that the database is not inadvertently altered. These safeguards include restrictions on the vendor application software and the Hanford application software.

Each version of Vendor and Hanford application software will be controlled. As a minimum, each version will have a new version identification number. Release for use will be accomplished by completely ident ifying the platform, the program, and all files in a supporting document in accordance with WHC-CM-6-1. See section 4.4 of this plan for details of the information required. New versions and changes to Hanford application software will be archived and retrievable as they are approved and released.

Revisions to the Vendor and Hanford application software and related supporting documents require an ECN, which is processed in accordance with WHC-CM-6-1. Revision will not be allowed until verification and validation is completed in accordance with an approved test plan. Superseded versions of vendor software will be archived and retrievable when necessary.

\subsection{DATA CONTROL}

\subsubsection{Functional Control of Data}

Data must meet the appropriate structure to be accepted by the HSTBD. Access to the database (Read/Write authorization) is controlled by Site Technical Integration. Checks are made by the database against the program template for the data. Error identification will require correction for acceptance of the data. 


\subsubsection{Administrative Control of Data}

Read/write data entry into the HSTBO will be controlled by the Manager of Site Technical Integration. Only personnel authorized by the Manager of Site Technical Integration will enter data into the database. Access control is established through password and name identification after appropriate training is provided.

There are four levels (regions) of control for the HSTBD. These include Test and Development, Validation, Pending, and Released-for-Use as reflected by Figure 1. Prior to being implemented in the Released-for-Use region all changes are documented, validated, reviewed, and approved. Database modification requires that performance be validated to meet requirements specified for a change without degrading the database operation or the data.

\section{Figure 1. HSTBD Control Regions}

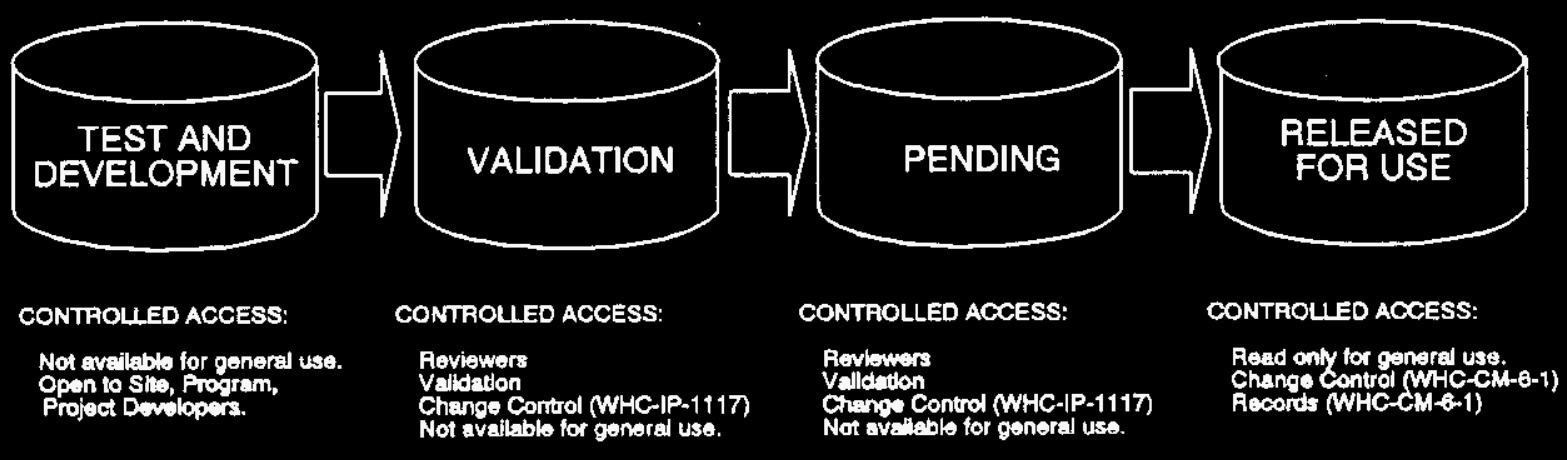

1. Test and Development. The Test and Development region of the database is the portion of the database available for use by authorized Site, Program, and Project developers. This region is for development and test purposes and may differ from the released HSTB. The Test and Development region is under access control such that it is not available for general use and does not require formal change control.

2. Validation. The Validation region of the database contains data or application software that is undergoing review and validation. This region may differ from the released HSTB and is not available for general use. The Validation region is under change control and controlled by the respective coordinating System Engineer. The changes undergoing review/validation are tracked by the HSTB CCA. Before being moved to the pending region, all changes must be documented, validated, reviewed, and approved by the Manager of Site Technical Integration.

3. Pending. The Pending region of the database contains data that has been approved and is pending release. This region may differ from the released HSTB and is not available for general use. The Pending region is under change control and controlled by the HSTB System Administrator. 
Changes to the Pending region require an approved Change Request (CR). These changes are tracked by the HSTB Change Control Administrator.

4. Released-for-Use. The Released-for-Use region of the database contains the data that makes up the current HSTB. This region is under full change control and is available as "Read Only" for general use. The HSTBD System Administrator has sole "Write" authority and is responsible for control of the released version of the HSTBD (CCP-03). This is the region that is used for producing baseline documents.

\subsection{HANFORD SITE TECHNICAL BASELINE DATABASE VERSION CONTROL} follows:

Three copies of the released version of the HSTBD will be maintained as

1. The System Administrator will maintain two copies of Hanford application software and data in separate locations (e.g., one maintained at 2440 Stevens Center by the Hanford Site Technical Baseline Database Systems Administrator and one kept by the BCSR Systems Administration organization).

2. The third copy of Hanford application software and data will be stored by BCSR. This will be accomplished by releasing the software as a supporting document in accordance with WHC-CM-6-1. The supporting document will include text pages that provide the following information.

a. Hanford Application Software and Data. File control information consisting of:

- Directory structure

- File name

- File size

- Date file was created

- Time file was created.

b. Vendor Application Software. Program/file control information consisting of:

- Name of program/file

- Program/file identification number (if applicable)

- Program/file version identification number (if applicable)

- Directory structure

- List of files (name, size, date created, and time created)

c. Platform. Platform control information consisting of (as applicable) :

- Type of computer

- Type of CPU

- Operating system

- Memory manager and setup if unique

- Minimum memory

- Minimum hard drive size

- Required floppy drive 
- Type of network and its setup if used

- Any other unique hardware and software needs.

\subsection{PROCEDURE REQUIREMENTS}

Procedures are needed to address specific requirements and associated responsibilities of the systems engineering manager, database managers, and database administrators regarding the control and modification of the HSTBD. The procedures will address the following.

- Unique identification of controlled software and related documentation.

- Unique identification of administrative documentation.

- Unique identification of change packages.

- Approval of changes to the software and related documentation.

- Approval and release of new documents as they are produced.

- Release of the revised HSTBD and documentation.

- Distribution of documents and of revisions to the HSTBD.

- Verification and validation of installed changes to the HSTBD.

- Status of the HSTBD and related documentation.

- Status of administrative documentation through updates to the document list.

- Status of HSTBD changes.

- Training of HSTBD operators and users.

The following specific documentation is to be developed and/or controlled.

- Vendor user manuals (vendor information).

- HSTBD user's guide.

- HSTBD Design Description.

- Test plan for software design (including software test descriptions, e.g., test cases and test procedures).

- RDD-100 report summary (part of user's guide).

- Training plans and procedures.

- $\quad$ Systems Engineering document 1 ist.

- Version Description Matrix. 


\subsection{REFERENCES}

1. DOE-STD-1073-93, "Guide for Operational Configuration Management Program," U.S. Department of Energy, Washington, D.C.

2. WHC-CM-2-5, Management Control System.

3. WHC-CM-3-5, Document Control and Records Management Manua7, Section 5.0, "Records Storage, Retrieval, and Destruction."

4. WHC-CM-3-10, Sof tware Practices.

5. WHC-CM-6-1, Standard Engineering Practices.

EP-1.1, "Engineering Document Identification."

EP-1.5, "Interface Control."

EP-1.7, "Engineering Document Approval and Release Requirements." EP-4.1, "Design Verification."

6. WHC-EP-0722, "Systems Engineering Functions and Requirements for the Hanford Cleanup Mission: First Issue." 


\subsection{BIBLIOGRAPHY}

1. DOE 4700.0, "Project Management System," U.S. Department of Energy, Washington, D.C.

2. DOE 5700.6C, "Quality Assurance," U.S. Department of Energy, Washington, D.C.

3. RLID 5000.12, "Richland Field Office - Hanford Site Management System, U.S. Department of Energy, Richland Operations Office, Richland, Washington.

4. RLIP 4700.1A, "Project Management System," U.S. Department of Energy, Richland Operations office, Richland, Washington.

5. RLPD 4900.1, "Systems Engineering," U.S. Department of Energy, Richland Operations Office, Richland, Washington. 


\section{GLOSSARY}

Approval - The dated signature that indicates an engineering document meets the requirements of the applicable discipline or assigned area of responsibility.

As-Built - Documentation (for example, Piping and Instrument Diagrams, and database records) verified by physical inspection as depicting the actual physical configuration and verified as consistent with the design requirements.

Assessment - For engineering applications, the process of estimating the value of something using authoritative expert judgement based on observations of representative cases and rough calculations, rather than determining the exact value based on comprehensive and detailed examinations, and precise and rigorous complete calculations.

Baseline - A set of documented decisions that constitute an established reference position for control, status accounting, reviews, assessments, and programmatic documents that are identified and controlled. Baselines are continually changing via an orderly control of changes as required by DOE-HQ, $\mathrm{RL}$, and the configuration management programs, especially during the development phase. Therefore, the current baseline is always the previously approved baseline with all approved changes.

Change - Any alteration or addition, temporary or permanent, to the physical configuration, computer software, configuration management documentation, or design requirements. Changes not within current design requirements involve design changes. Identical replacements are not changes.

Change Control - A process that ensures all changes are properly identified, reviewed, approved, implemented, tested, and documented.

Change Boards - A board composed of technical and administrative representatives who review, approve, disapprove, or defer changes to an approved cost, schedule, or technical baseline. These boards may be established by the WHC program, contractors, or individual projects.

Change Request - The document used to initiate changes to approve program cost, schedule, and technical baselines and uniquely identified by a change identification number.

Computer Software - Computer programs, procedures, and possibly associated documentation and data pertaining to the operation of a computer system. This includes user-provided instructions and data that implement preprogrammed algorithms in control systems; computer codes and data that will reside in firmware; and where specified by the cognizant manager, userprovided instructions and data used by commercial software such as spreadsheet and database packages. 


\section{GLOSSARY (continued)}

Configuration - The functional and/or physical characteristics of hardware, firmware, or software as delineated in technical documentation and achieved in a product (form, fit, and function).

Configuration Management - An integrated management program that establishes consistency among requirements, physical configuration, and documentation (including electronic data), and maintains this consistency throughout the life of the facility as changes occur. The CM program consists of $\mathrm{CM}$ functions associated with the following program elements: program management, design requirements, document control, change control, and assessments. The CM program also includes design reconstitution and material condition and aging management as adjunct programs.

Deactivation - The process of permanently ceasing active operation of an SSC in a planned and controlled manner. A deactivated SSC will be adequately prepared to support ongoing surveillance and maintenance activities and the subsequent decontamination activities performed by Decontamination and Decommissioning.

Design Authority - The organization responsible for establishing the design requirements and ensuring that design output documents appropriately and accurately reflect the design basis. The design authority is responsible for design control and ultimate technical adequacy of the engineering design process. These responsibilities are applicable whether the process is conducted fully in-house, partially contracted to outside organizations, or fully contracted to outside organizations.

Design Basis - Consists of the design inputs, the design constraints, and the design analys is and calculations. It includes topical areas such as seismic qualification, fire protection, and safe shutdown. The design basis encompasses consideration of factors such as facility availability, facility efficiency, costs, and maintainability, and that subset that relates to safety and the authorization basis. The design basis explains why a design requirement has been specified in a particular manner or as a particular value.

Design Change - Any revision or alteration of the technical requirements defined on approved and released design output documents and approved and issued changes thereto.

Design Documents - Those documents that define either the design requirements or the design basis of the facility. Design documents include design specifications, design change packages, design drawings, design analys is, setpoint calculations, summary design documents, correspondence with DOE that provides design commitments, and other documents that define the facility design.

Design Reconstitution - An adjunct program to the CM program that accomplishes the one-time effort of identifying, retrieving, extracting, evaluating, verifying, validating, and regenerating missing critical design requirements and basis. Design reconstitution encompasses the 
following functions: developing associated program plans and procedures; identifying and retrieving design information from identified source documents; evaluating, verifying, and validating the design information; resolving discrepancies; regenerating missing critical design information; and preparing and issuing Design Information Summaries.

Design Requirements - Those engineering requirements reflected in design output documents (such as drawings and specifications) that define the functions, capabilities, capacities, physical sizes and dimensions, limits and setpoints, etc., specified by design engineering for a structure, system, or component. The design requirements provide the results of the design process.

Desian Verification - The process of reviewing, testing, checking, and/or otherwise determining and documenting whether a design conforms to specified requirements and is adequate for its intended application.

Document Control - A process that stores and controls, tracks status (especially during revisions), and retrieves documents.

Electronic Data - Specific systems engineering information collected and manipulated within the database.

Graded Approach - A process by which the level of analysis, documentation, and actions necessary to comply with a requirement are made commensurate with many considerations, including the relative importance to safety, safeguards, and security; the magnitude of any hazard involved; the 1 ife cycle stage of a facility; the programmatic mission of a facility; the particular characteristics of a facility; and any other relevant factor.

Hanford Site Application Software - Software that has been designed for Hanford specific use within the Hanford Site Technical Baseline Database.

Hanford Site Technical Basel ine Database - The primary database used to manage and maintain the Hanford Site Technical Basel ine information.

Interface Control Drawings - Drawings that document and control the data and information delineating interface boundaries.

NOTE: These interface control drawings are used to identify and define physical and functional interfaces that require coordination to establish and maintain compatibility between the co-functioning items of equipment, computer software and facilities; control design features, which, if changed, would affect compatibility between co-functioning equipment or the facility; and communicate essential design decisions and changes to affected design activities. 


\section{GLOSSARY (continued)}

Material Condition \& Aging Management - An adjunct program to the CM program that encompasses the functions of: developing associated program plans and procedures; screening components to determine those that are potentially life-limiting for the facility; evaluating, aging degradation mechanisms; estimating the facility remaining lifetime; evaluating feasibility of continued operations and extended operations; performing detailed material condition and aging analysis; and developing necessary life extension techniques to achieve the facility desired lifetime defined by DOE.

Phased Implementation - Involves establishing priorities, milestones with deliverable products, and implementation schedules within the context of the amount of resources and funding that can reasonably be expected to be available.

Physical Configuration - The actual physical location, arrangement, and material condition of structures, systems, and components within a facility.

Program Management - The process of defining program objectives, identifying actions/tasks to accomplish those objectives, estimating the level of effort needed to complete each task, organizing and scheduling the planned tasks, staffing an organization to accomplish the planned tasks, assigning personnel to specific tasks, monitoring progress during the implementation, identifying problems and taking corrective actions, and recognizing tasks and program completion.

Release - An activity that certifies by a stamp that the engineering document is the controlled version, approved for the intended use, entered in a database, and retrievable.

Schema - Data that establishes the plan of action for an orderly combination of the data elements to fit the program (similar to program software).

Structures, Systems, and Components - Structures are elements that provide support or enclosure such as buildings, free standing tanks, basins, dikes, and stacks. Systems are collections of components assembled to perform a function such as piping, cable trays, conduit, or HVAC. Components are items of equipment such as pumps, valves, relays, or elements of a larger array such as computer software, lengths of pipe, elbows, or reducers.

Supporting Documents - An engineering text document that describes, defines, reports, or certifies activities, requirements, procedures, or results of engineering activities that support the WHC onsite missions.

NOTE: Other technical work may use the SD system of identification, review, release, and change control. 


\section{GLOSSARY (continued)}

Systems Engineering - The systematic approach used by management and engineering to transform technical goals into an optimized, integrated, operational, and physical system that achieves the mission. The iterative technical and management process applied throughout the system life cycle that produces and maintains a well-defined and documented system technical basel ine.

Technical Baseline - The defined and approved physical/functional configuration (requirements and design description) of an SSC or computer software that is used as a reference for program planning purposes and as a point of departure for change control. The technical baseline plus approved changes, waivers, and deviations constitutes the current configuration.

Vendor Information - Any type of technical documentation/information submitted by a vendor as part of a procurement.

Verification - For the design reconstitution program, the process of checking that the retrieved design information has been completely and accurately translated from the source documents. 